\title{
Microbial Communities in Globodera pallida Females Raised in Potato Monoculture Soil
}

\author{
Caroline Eberlein, Holger Heuer, Stefan Vidal, and Andreas Westphal
}

First and fourth authors: Institute for Plant Protection in Field Crops and Grassland, Julius Kühn-Institut, D-38104 Braunschweig, Germany; second author: Institute for Epidemiology and Pathogen Diagnostic, Julius Kühn-Institut, D-38104 Braunschweig, Germany; and third author: Department of Crop Sciences, University of Göttingen, 37077 Göttingen, Germany.

Current address of fourth author: University of California Riverside, Department of Nematology, Kearney Agricultural Research and Extension Center, Parlier, CA 93648.

Accepted for publication 30 January 2016.

\begin{abstract}
Eberlein, C., Heuer, H., Vidal, S., and Westphal, A. 2016. Microbial communities in Globodera pallida females raised in potato monoculture soil. Phytopathology 106:581-590.

Globodera spp. are under strict quarantine in many countries. Suppressiveness to cyst nematodes can evolve under monoculture of susceptible hosts. Females developing in potato monoculture soil infested with G. pallida populations Chavornay or Delmsen were examined for inherent microbial communities. In the greenhouse, nonheated and heat-treated $\left(134^{\circ} \mathrm{C}\right.$ for $10 \mathrm{~min}$ ) portions of this soil were placed in root observation chambers, planted with Solanum tuberosum 'Selma', and inoculated with G. pallida $\mathrm{Pa} 3$ Chavornay. At harvest in Delmsen soil, cysts had fewer eggs in nonheated than

heat-treated soil. In denaturing gradient gel electrophoresis analysis, bacterial and fungal fingerprints were characterized by a high variability between replicates; nonheated soils displayed more dominant bands than heated soils, indicating more bacterial and fungal populations. In amplicon pyrosequencing, females from nonheated portions frequently contained internal transcribed spacer sequences of the fungus Malassezia. Specific for the Chavornay and Delmsen population, ribosomal sequences of the bacteria Burkolderia and Ralstonia were abundant on eggs. In this first report of microbial communities in G. pallida raised in potato monoculture, candidate microorganisms perhaps associated with the health status of the eggs of G. pallida were identified. If pathologies on cyst nematodes can be ascertained, these organisms could improve the sustainability of production systems.
\end{abstract}

Potato (Solanum tuberosum L.) is one of the most consumed vegetable crops worldwide and also serves as an important source of biological renewable raw material, e.g., starch (FAO 2008). Of the factors that constrain the production of potatoes, nematodes, especially the potato cyst nematodes ( $\mathrm{PCN}$ ) Globodera pallida (Stone) Behrens and G. rostochiensis (Wollenweber) Behrens, are among the most important limiting pests (Scurrah et al. 2005). The severe yield reduction potential of Globodera spp. has resulted in classification of PCN as quarantine pests within the European Union, for member countries of the Asia and Pacific Plant Protection Commission (APPPC), and the North American Plant Protection Organization (NAPPO) (CABI/EPPO 1997). In North America, after detected in 1941 on Long Island, New York, G. rostochiensis was subjected to strict quarantine regulations under the Golden Nematode Act. In 2006, G. pallida was discovered in northern Bingham County, Idaho. Currently, G. rostochiensis and G. pallida are of limited distribution in New York and Idaho states, respectively, and under official control (USDA/APHIS 2015). In Europe, legislative control measures aim at preventing further spread and multiplication to damaging levels (European Union 2007). Consequently, all fields scheduled for production of seed potatoes must be inspected and found to be free of infestations with Globodera spp. before the crop may be grown. If any of these nematodes are found, seed potato production is prohibited, and management options are put in place that aim at reducing population densities of the nematode. For example, cropping of consumption potatoes with resistance to the specific Globodera spp. can be prescribed by the local plant protection service.

Corresponding author: A. Westphal; E-mail address: andreas.westphal@ucr.edu

http://dx.doi.org/10.1094/PHYTO-07-15-0180-R

(C) 2016 The American Phytopathological Society
Currently, few alternatives other than the use of resistant cultivars are available for the management of these nematodes. Effectiveness of crop rotation is limited, particularly for G. pallida, due to the slow decline of populations in the absence of a host crop (Evans and Haydock 2000), resulting in the mandating of long and impractical rotations. The use of trap crops like Solanum sisymbriifolium Lam. has been successful to reduce PCN in the Netherlands (Scholte 2000) but implementation remains slow because of undesirable thorns on the plants and the risk that this plant produces seeds that could germinate within potato crops where weeds of Solanum spp. are difficult to control. Use of brassica cover crops seems promising but is still in experimental stages (Ngala et al. 2015). When available and cost effective, fumigant nematicides such as 1,3-dichloropropene or methyl bromide were used for PCN control. Currently, fumigant nematicides are generally banned in Europe. In developed countries, methyl bromide has been banned since 2005, except for some highly restricted critical uses. Nonfumigant granular nematicides, e.g., fosthiazate, can reduce yield loss but do not suppress nematode population densities throughout the growing season (Woods et al. 1999). Nematode population density reduction is a mandatory regulatory requirement for prescribed management strategies, and thus nematostatic, nonfumigant nematicides may not be used. As a result, potato production systems rely heavily on resistant cultivars. The utility of resistant cultivars is widely recognized but there is a lack of sufficient cultivars against some pathotypes of PCN, especially for G. pallida (CABI/EPPO 1997). The use of resistant cultivars also exerts a selection pressure. For example in Europe, the use of resistant cultivars that incorporate the $H_{1}$ gene resistance to $G$. rostochiensis facilitate the increase of G. pallida from previously mixed populations, shifting predominance to the species that is not suppressed by the potato cultivar (Evans and Haydock 2000). A shift in nematode virulence could also occur, where the evolution of a new pathotype on a previously 
effective nematode resistance gene in potato threatens the sustainability of resistance as a management strategy (Schouten and Beniers 1997). Overcoming these risks of current management strategies demands alternative methods for growing potato in infested PCN fields.

PCN live in a microbiologically complex soil environment. Equilibrium of plant-parasitic nematode population density and antagonistic microorganisms is hypothetically found in undisturbed soils or in soils with continued cropping of a susceptible host (Stirling 1991; Westphal 2005). Since the discovery of soils suppressive to Heterodera avenae Woll. in the U.K., monoculture of susceptible host plants of the specific nematode pest is viewed as a prerequisite for the evolution of suppressive soil (Gair et al. 1969). Several examples of suppressive soils have been reported for cyst nematodes (Kerry and Crump 1998; Westphal and Becker 1999; Westphal and Xing 2011). In most of these soils, the reproduction of plant-parasitic nematodes was constrained by the activity of antagonistic microorganisms. In the specific case of the cereal cyst nematode, suppressiveness was caused by Nematophthora gynophila and Pochonia chlamydosporium, two parasitic fungi that rendered this nematode a non-problem in years of suitable soil moisture conditions in the U.K. (Kerry et al. 1982). In soils with Heterodera schachtii Schm. in California, Brachyphoris (syn. Dactylella) oviparasitica was identified as the key player in suppressiveness (Borneman and Becker 2007). Research on potential suppressive soils against Globodera spp. has received limited attention (Crump and Flynn 1995; Roessner 1987).

The objective of this study was to test whether an unusually high number of diseased G. pallida eggs found under potato monoculture (C. Eberlein, unpublished data) was associated with specific microbial communities in the eggs of G. pallida raised in this monoculture soil. The microbial communities present within the eggs of females developing in this monoculture soil were characterized using cultivation-independent techniques.

\section{MATERIALS AND METHODS}

Development of $G$. pallida females in root observation chambers. Soils from a potato monoculture at the Julius KühnInstitut at Münster were collected from a microplot study, where potatoes were grown from 2009 until 2014 in plots filled with sandy soil ( $90.0 \%$ sand, $5.4 \%$ silt, $2.4 \%$ clay, $2.2 \%$ O.M., pH 6.2) infested with G. pallida populations (1) Chavornay or (2) Delmsen. In this monoculture, microbial communities in the Delmsen plots had been perturbed with the application of dazomet at $500 \mathrm{~kg} / \mathrm{ha}$ in April 2010 (tetrahydro-3,5-dimethyl-1,3,5-thiadiazine-2thione; Basamid, BASF, Ludwigshafen, Germany) (C. Eberlein, unpublished data). Two independent greenhouse experiments were set up in a randomized complete block design with five replications, with a factorial arrangement of soil infestation (1) or (2), and two treatments of the following: (i) nonheated and (ii) steam heat-treated at $134^{\circ} \mathrm{C}$ for $10 \mathrm{~min}$ in an autoclave. The heating was done to perturb microbial communities possibly associated with diseased eggs

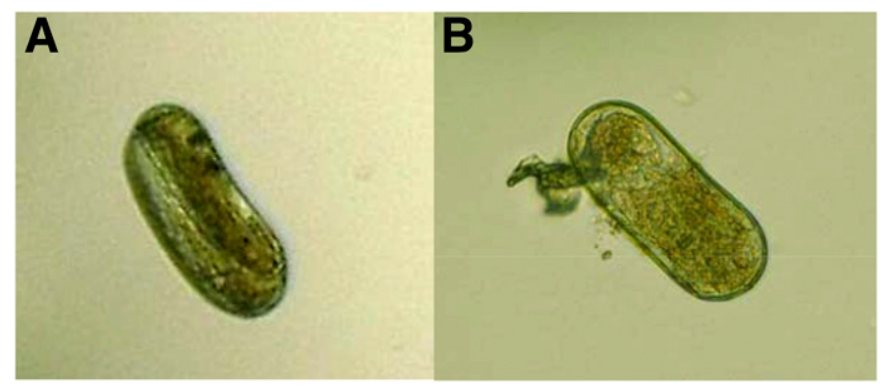

Fig. 1. Egg of Globodera pallida A, healthy and B, compromised, rated as diseased. detected in this monoculture soil (Westphal 2005). For the first of these experiments, soil samples were collected during the fall of 2011, from microplots of both $G$. pallida populations to a depth of $30 \mathrm{~cm}$. For the replication of this experiment, soil samples from the same microplots were collected in spring 2014. In the second run of the experiment, a loam soil (50.3\% sand, $30.2 \%$ silt, $9.5 \%$ clay, $1.42 \%$ O.M., pH 6.6) with no potato crop history was included as a control.

At initiation of the respective experiments, soils were separated into two portions, one was left nonheated, and the other steam heattreated. Both portions were then placed in separate root observation chambers with an $18 \mathrm{~cm} \times 13 \mathrm{~cm}$ transparent side and $6 \mathrm{~cm}$ depth. Each chamber was inoculated with cysts of $G$. pallida $\mathrm{Pa} 3$ population Chavornay at the equivalent of 12,000 eggs per box, and planted with a sprouted seed piece of potato 'Selma'. The boxes were leaned at a 45-degree angle with the transparent side down, so roots grew preferentially against this side to allow for observation of the root system and developing females. The experiments were maintained under ambient light with day and night averaged temperatures of 23 and $22^{\circ} \mathrm{C}$ (first experiment) and 25 and $23^{\circ} \mathrm{C}$ (second experiment), in a temperature controlled greenhouse. The chambers were watered daily with tap water and fertilized with nutrient solution (NPK: $5.3 \%$ N, 3.9\% P, and 19.7\% K) (Steiner 1968) as needed once a week. Starting at 36 and 35 days postinoculation (dpi), in the first and second experiment, respectively, females visible on the root surface were counted weekly. At 64 and 91 dpi in the first and second experiment, respectively, 10 individual females were hand-picked from the root system of each box, washed with sterile water, and stored at $-20^{\circ} \mathrm{C}$ for microbial community analysis. At the termination of the first experiment (101 dpi) and second experiment (91 dpi), females and cysts hand-picked from the roots were used for examination of the egg contents. The visible root length per root box was determined using the line intersection method (Tennant 1975) at 86 and 77 dpi in the first and second experiment, respectively.

Examination of the egg content of females and cysts. Females and cysts picked from the root system at 101 and $91 \mathrm{dpi}$ in the first and second experiment, respectively, were thoroughly washed with sterile water and divided into two groups for different examinations. Females and cysts belonging to the first group were crushed to release eggs and second-stage juveniles (J2) that were spread onto water agar $(5 \%)$ amended with the antibiotic rifampicin $(100 \mathrm{mg} / \mathrm{kg})$ in $9-\mathrm{cm}$-diameter petri plates. After 3 days of incubation at room temperature, eggs and $\mathrm{J} 2$ with visible fungal infestation were counted and numbers expressed as percentages of the total number of eggs and $\mathrm{J} 2$ observed. Females and cysts of the second group were also crushed, and the obtained egg suspensions were examined and categorized into healthy (normally developed, intact J2 inside; Fig. 1A) or diseased (abnormal development or obviously colonized by microbes; Fig. 1B) under an inverted transmitted light microscope (63x magnification). Percentages of diseased or healthy eggs and $\mathrm{J} 2$ of the total number of eggs and $\mathrm{J} 2$ examined were calculated.

DNA extraction and PCR amplification of bacterial 16S rRNA gene and fungal internal transcribed spacer (ITS) fragments from $G$. pallida females. Genomic microbial DNA from the egg content of 10 females per root chamber was extracted with the FastDNA SPIN Kit for soil by using the FastPrep-24 bead beating system (MP Biomedicals, Santa Ana, CA) according to manufacturer recommendations. Extracted DNA was checked by electrophoresis $(80 \mathrm{~V}, 45 \mathrm{~min})$ on a $0.8 \%$ agarose gel followed by ethidium bromide staining, and viewing under UV light. DNA was stored at $-20^{\circ} \mathrm{C}$ until further use.

The bacterial specific primers F984GC and R1378-1401 were used for amplification of 16S rRNA gene fragments (Heuer et al. 1997). PCR reactions were performed in $25-\mu \mathrm{l}$ reaction volumes, containing $5 \mu \mathrm{l}$ of $5 \times$ GoTaq buffer, $2.5 \mu \mathrm{l}$ of $2 \mathrm{mM}$ dNTPs, $3.75 \mu \mathrm{l}$ of $25 \mathrm{mM}$ $\mathrm{MgCl}_{2}, 2 \mu \mathrm{l}$ of $50 \%$ (wt/vol) acetamide, $0.5 \mu \mathrm{l}$ of $10 \mu \mathrm{M}$ of each primer, $0.125 \mu \mathrm{l}$ of GoTaq polymerase at $5 \mathrm{U} / \mu \mathrm{l}$ (Promega, Madison, WI), $9.625 \mu \mathrm{l}$ of distilled water, and $1 \mu \mathrm{l}$ of template DNA. After 5 min 
of denaturation at $94^{\circ} \mathrm{C}, 35$ thermal cycles including $1 \mathrm{~min}$ at $94^{\circ} \mathrm{C}$, $1 \mathrm{~min}$ at $53^{\circ} \mathrm{C}$, and $2 \mathrm{~min}$ at $72^{\circ} \mathrm{C}$ were performed, followed by a final extension at $72^{\circ} \mathrm{C}$ for $10 \mathrm{~min}$. Positive amplification was confirmed by electrophoresis on $1 \%$ agarose gels with ethidium bromide staining.

The fungal ITS fragments were amplified using a nested PCR with primer pairs ITS1F/ITS4 and ITS1FGC/ITS2 according to the PCR conditions described by Weinert et al. (2009) with slight modifications. Aliquots of $2 \mu \mathrm{l}$ of the first stage PCR products were used as template for the subsequent PCR. Amplicons were analyzed by $1 \%$ agarose gel electrophoresis, ethidium bromide staining, and UV light.

Denaturing gradient gel electrophoresis (DGGE) analysis of the amplified bacterial and fungal amplicons from G. pallida females. DGGE (Muyzer et al. 1993) was used to assess the composition of the dominant bacterial and fungal communities present in the eggs recovered from the extracted females. PCR products were separated by DGGE based on the protocol of Weinert et al. (2009). Briefly, polyacrylamide gels with denaturing gradients of 46.5 to $65 \%$ and 23 to $58 \%$ (100\% denaturant is defined as $7 \mathrm{M}$ urea and $40 \%$ de-ionized formamide) were used for 16S rRNA and ITS fragments of bacteria and fungi, respectively. Electrophoresis was performed using the IngenyphorU system (Ingeny, Goes, The Netherlands). The volume of PCR products loaded on the gel was adjusted according to the amplicon concentration as assessed by agarose gel electrophoresis (3 to $10 \mu \mathrm{l})$. The electrophoresis was run in $1 \times$ tris-acetate-EDTA buffer for $17 \mathrm{~h}$ at $58^{\circ} \mathrm{C}$ and $140 \mathrm{~V}$ for PCR-amplified 16S rRNA gene fragments, and for $18 \mathrm{~h}$ at $60^{\circ} \mathrm{C}$ and $100 \mathrm{~V}$ for ITS fragments. The gels were silver-stained (Heuer et al. 2001), dried at room temperature, and scanned with a digital flat bed scanner.

Cluster analysis of bacterial and fungal community profiles was conducted with the software package GelCompar II 6.5 (Applied Maths, Gent, Belgium) to evaluate the percentage of similarity shared among samples. Lanes were normalized and similarities for each pair of lanes within a gel were determined using Pearson's correlation. A cluster analysis was performed by the unweighted pair group method using arithmetic averages (UPGMA).

The bacterial and fungal fingerprints of nonheated and heattreated soil from the experiment consisting of Chavornay and Delmsen microplot soils and those of inoculum cysts were compared. This was done to test whether the microorganisms in the females that developed in the nonheated and the heat-treated soils were acquired from the soil environment rather than being transmitted from the cyst inoculum.

Pyrosequencing and sequence analysis of DNA from G. pallida females raised in nonheated potato monoculture soil. In preparation of the pyrosequencing process, bacterial $16 \mathrm{~S}$ rRNA gene fragments were amplified in $25 \mu \mathrm{l}$ of PCR mixtures of $2.5 \mu \mathrm{l}$ of TrueStart buffer, $3.75 \mu \mathrm{l}$ of $25 \mathrm{mM} \mathrm{MgCl}_{2}, 2.5 \mu \mathrm{l}$ of $2 \mathrm{mM}$ dNTPs, $1.25 \mu \mathrm{l}$ of DMSO, $0.75 \mu \mathrm{l}$ of $10 \mu \mathrm{M}$ primers $356 \mathrm{~F}$ and 1064R, $0.125 \mu \mathrm{l}$ of TrueStart Hot Taq DNA polymerase at $5 \mathrm{U} / \mu \mathrm{l}$ (Thermo Scientific, Schwerte, Germany), $10.37 \mu$ of distilled water, and $1 \mu \mathrm{l}$ of template DNA. The following thermocycling program was used: 5 min denaturation at $95^{\circ} \mathrm{C}$, followed by 35 cycles of $30 \mathrm{~s}$ denaturation at $95^{\circ} \mathrm{C}, 30 \mathrm{~s}$ annealing at $60^{\circ} \mathrm{C}, 1 \mathrm{~min}$ extension at $72^{\circ} \mathrm{C}$, and a final extension step of $10 \mathrm{~min}$ at $72^{\circ} \mathrm{C}$. These PCR products and those from the first step of the nested ITSPCR were purified with the DNA Clean \& Concentrator-5 Zymo Kit (Zymo Research Corporation, Irvine, CA) before being submitted for pyrosequencing. Sequencing of the hypervariable V3-V4 region of the 16S rRNA gene was conducted at the Biotechnology Innovation Centre (BIOCANT, Cantanhede, Portugal) with fusion primers containing the Roche-454 A and B Titanium sequencing adapters, an eight-base barcode sequence in fusion primer $\mathrm{A}$, the forward primer $5^{\prime}$-ACTCCTACGGGAGGCAG-3', and the reverse primer 5'-TACNVRRGTHTCTAATYC-3' (Wang and Qian 2009). For the ITS2 region of fungal ribosomal DNA, amplifications were performed with fusion primers containing the Roche-454 A and B
Titanium sequencing adapters, an eight-base barcode sequence in fusion primer $\mathrm{A}$, the forward primer $5^{\prime}$-GCATCGATGAAGAA CGC-3', and reverse primer 5'-CCTCCGCTTATTGATATGC-3' (White et al. 1990). Sequencing was performed with GS 454 FLX Titanium chemistry, according to manufacturer's instructions (Roche, 454 Life Sciences, Brandford, CT).

In the case of bacteria, quality filtered sequences were assigned to operational taxonomic units (OTUs) defined at $97 \%$ sequence similarity according to Ding et al. (2012). Briefly, sequences matching the barcode and primer were selected for blastn searches in the database SILVA 115 SSU Ref (Quast et al. 2013). Chimera were truncated, barcodes and primers were removed, and sequences shorter than $200 \mathrm{bp}$ were discarded. Multiple alignments and OTU assignment were performed using the software package Mothur v1.14.0 (Schloss et al. 2009). Fungal ITS2 sequences were assigned to the most similar ITS of "species hypotheses" $(\mathrm{SH})$ as defined in the database UNITE v6 (Kõljalg et al. 2013), for sequences with an identity of at least $95 \%$. For ITS sequences that had the same similarity to more than one $\mathrm{SH}$, the $\mathrm{SH}$ with highest frequency in all blastn hits was chosen.

Statistical analysis. Analyses of variance were used to analyze the data with the MIXED and GLIMMIX procedures of SAS (version 9.3, SAS Institute, Cary, NC). Count data were $\log _{10^{-}}$ transformed, whereas any percentage data were arcsine-transformed before analysis in PROC MIXED. Females counted at weekly time intervals (response variable) were analyzed as repeated measures with PROC GLIMMIX. The model included the effects of soil, treatment and time. For the examination of the egg content of females and cysts, the effects of soil and treatment (independent variables) were tested on the dependent variables: percentages of healthy or disease eggs, eggs per cyst, and percentages of eggs presenting fungal growth. Statistical significance was set at $P \leq 0.05$. Results obtained from PROC MIXED are presented as means \pm SE. Results obtained from PROC GLIMMIX are presented as backtransformed lsmeans \pm lsmse.

\section{RESULTS}

Development of $G$. pallida females in root observation chambers. In the first experiment consisting of microplot soils where potato was repeatedly grown in the presence of Chavornay or Delmsen G. pallida populations, no significant differences in numbers of females were found between the two soils (Chavornay: $38.2 \pm 5.8$, Delmsen: $31.0 \pm 4.5, P=0.2841$ ), or between the two treatments (heat-treated: $35.6 \pm 5.4$, nonheated: $33.3 \pm 4.8, P=$

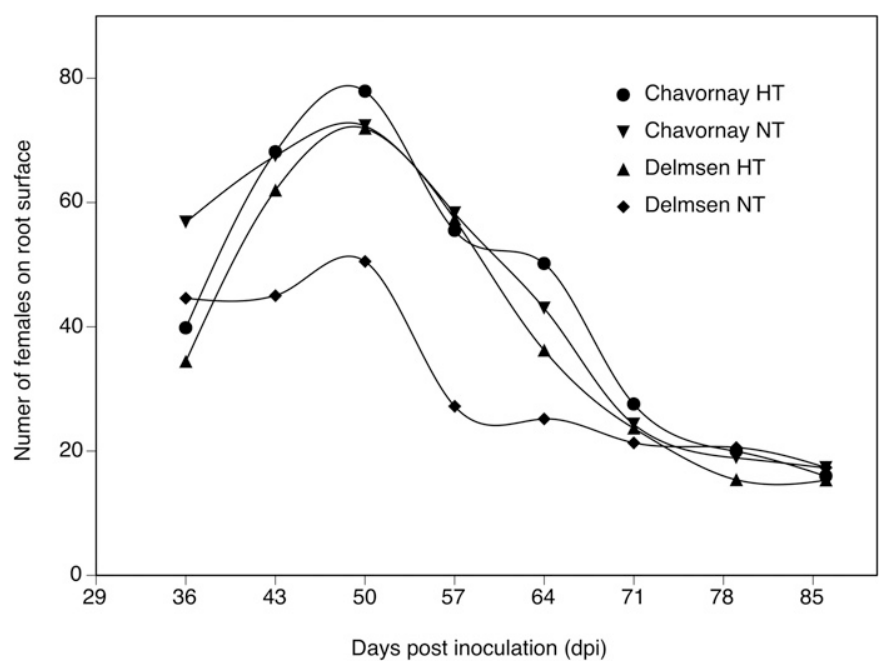

Fig. 2. Number of females visible on potato roots 'Selma' during monitoring in root observation chambers from 36 to 90 dpi of heated and nontreated portions of soil from Chavornay or Delmsen microplots during the first experiment. 
0.7215; data not shown) during the monitoring time. The root length measurements per observation area were similar in nonheated and heat-treated soils, or between Chavornay and Delmsen soils (data not shown). Maximum numbers of females visible on the roots were reached at $50 \mathrm{dpi}$, and declined until completion of the experiment (Fig. 2). In the replication of the experiment including a control soil lacking of a potato cropping history in the heat-treated soil, no significant differences were observed among soils. Within nonheated soils, female numbers were similar between the control $(5.8 \pm 1.9)$ and Chavornay $(11.6 \pm 3.5 ; P=0.1232)$, and higher in Delmsen $(52.5 \pm 15.0)$ than in the control $(P<0.01)$ and Chavornay $(P<0.01)$. In nonheated soil, female numbers in Chavornay remained similar at $35 \mathrm{dpi}(126.2 \pm 57.8)$ and $42 \mathrm{dpi}(79.8 \pm 33.7$; $P=0.2101)$, and thereafter decreased until $77 \mathrm{dpi}(2.2 \pm 0.9 ; P<$ $0.01)$ to remain similar through $91 \mathrm{dpi}(1.5 \pm 0.7 ; P=0.4064)$. In the
Delmsen population soil (in nonheated portion), female numbers remained similar from $35 \mathrm{dpi}(302.1 \pm 137.9)$ to $49 \mathrm{dpi}(216.7 \pm$ 110.5; $P=0.4160)$, thereafter decreasing until 91 dpi (5.1 \pm 1.6 ; $P<0.01)$. For both populations, maximum numbers of females were found at 35 dpi (data not shown).

Examination of the egg content of females and cysts of G. pallida. In the first experiment, the total number (healthy and diseased) of eggs per cyst in Delmsen population soil were only about half in the nonheated soil $(81.5 \pm 26.4)$ than in the heat-treated $(157.5 \pm 20.4, P<0.01)$. In nonheated soil, fewer eggs per cyst were found in Delmsen soil $(81.5 \pm 26.4)$ than in Chavornay soil $(143.6 \pm$ $10.9, P=0.0146)$. However, no significant effect of the treatment was detected on the percentages of diseased eggs. After incubation on water agar, only a few eggs showed fungal hyphae and no significant differences were found with regard to the percentages of

TABLE 1. Means \pm standard error of percentage of diseased eggs, number of eggs per cyst and eggs with fungal growth from the content of Globodera pallida females, and cysts raised in root observation chambers in potato monoculture soil infested with one of two G. pallida populations

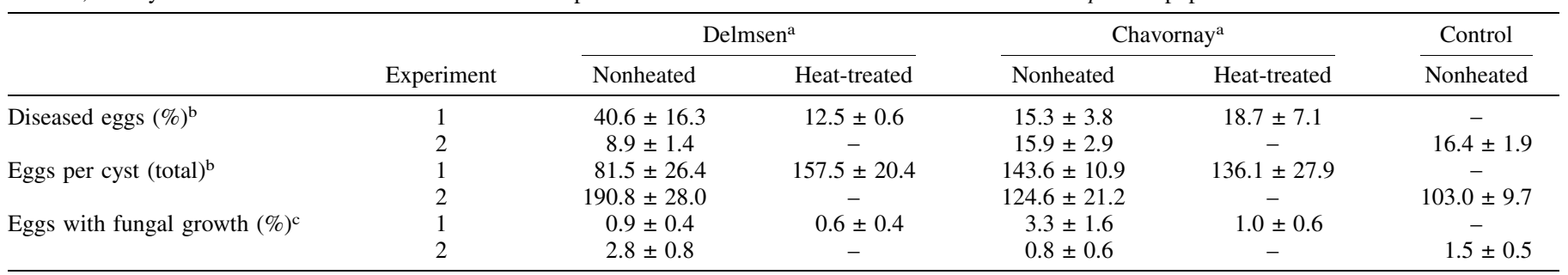

${ }^{a}$ Delmsen and Chavornay are G. pallida populations; control soil had no known previous history of potato cultivation.

b Microscopic observation immediately after preparation of egg suspensions.

${ }^{c}$ Microscopic observation after incubation for 3 days on water agar.

A

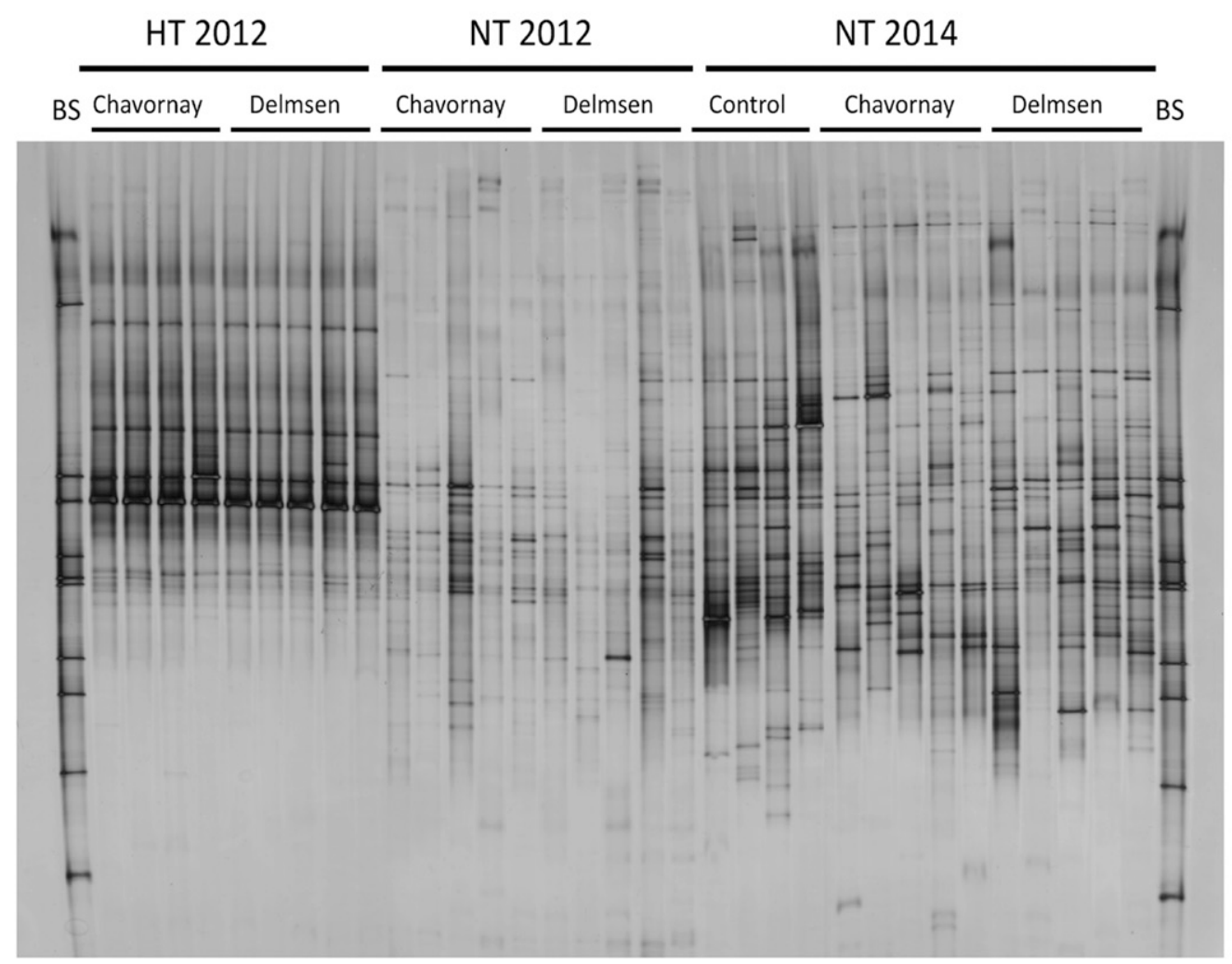

B

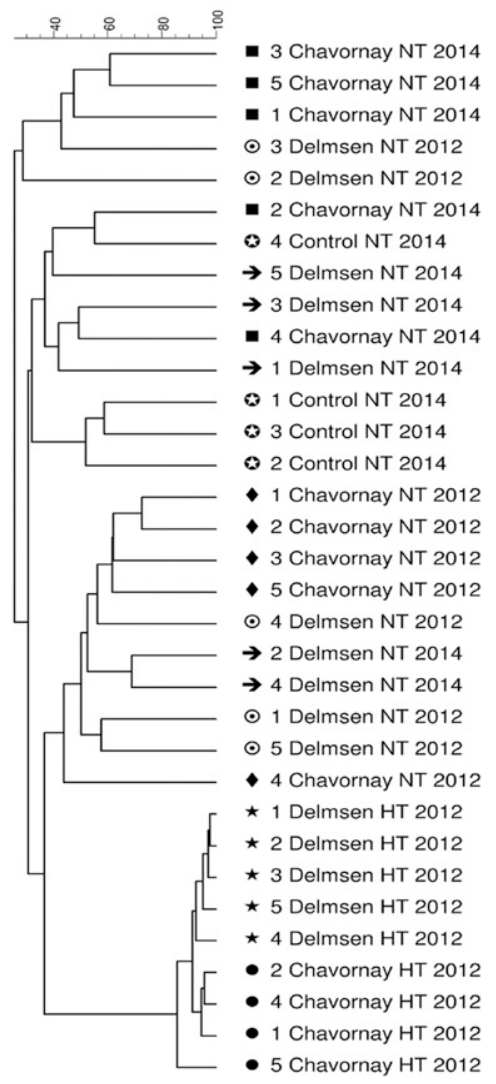

Fig. 3. A, Bacterial (16S rRNA gene) denaturing gradient gel electrophoresis fingerprints for Globodera pallida females collected from heat-treated (HT) and nonheated soil (NT) at 64 days postinoculation (dpi) in 2012 and at 91 dpi in 2014 and B, corresponding UPGMA cluster. Groups of five/four lines are replicates. BS: bacterial standard. In the dendrograms, replicates are labeled 1 to 5 . The scale shows similarity values. 
eggs with fungi from different soils (both experiments) or between the treatments (first experiment; Table 1).

DGGE analysis of the amplified bacterial and fungal amplicons from $G$. pallida females. In the DGGE fingerprints of bacterial communities, different profiles for nonheated and heattreated soil indicated the presence of different bacterial populations (Fig. 3A). DGGE fingerprints of 16S rRNA genes from heat-treated soil displayed a highly uniform pattern. In the UPGMA-cluster analysis, samples from the heat-treated soil shared more than $80 \%$ similarity and clustered separately from the nonheated soil (Fig. 3B). In nonheated soil, a different and complex pattern for the bacterial community was attributed to the high variability among replicates. A larger number of dominant bands compared with the heat-treated soil indicated an increase in dominant bacterial species (Fig. 3A). The high variability among replicates and the lack of separation between the two populations or experiments precluded detection of specific ribotypes enriched in the nonheated soil. These results were confirmed by UPGMA-dendrograms, where a mixed clustering between the $G$. pallida populations and the two experiments within the nonheated soil was observed (Fig. 3B).

In the community analysis of fungal ITS fragments, a different pattern was observed for the nonheated compared with the heattreated soil (Fig. 4A). In contrast to the bacterial profiles, a high variability within populations was observed in the heat-treated soil, where few high-intensity bands indicated that a few fungal species were dominant (Fig. 4A). In the ITS UPGMA-dendrogram, with the exception of one replication, the heat-treated soil formed a separate cluster but shared a low similarity (Fig. 4B). In nonheated soil, the highly complex banding resulted in no consistent clustering (Fig. 4B). In both experiments, higher abundance of dominant bands in nematodes from nonheated than heat-treated soil samples indicated an increase in dominant fungal ribotypes. The control soil displayed fewer dominant bands than soil from the two G. pallida populations (Fig. 4A). Despite the high internal variability of nonheated soils from each of the experiments, four dominant bands with identical electrophoretic mobility (A, B, C, and D) were observed in almost all samples from both populations (Fig. 4A). The ITS fragments pattern did not allow distinguishing the two populations and the two experiments. A higher abundance of dominant bands reflecting enhanced sequence diversity was observed in the fungal DGGE than in the bacterial DGGE.

Distinct fingerprints and clusters for bacterial DGGE results were observed for inoculum cysts and for females from heat-treated soil (Fig. 5A and B). Despite a high variability among replicates within inoculum cysts and the females from nonheated soil, bacterial DGGE fingerprints from most samples of females from nonheated soil clustered separately from the inoculum cysts and shared a low similarity with them (Fig. 5B). Different fungal fingerprints were observed for inoculum cysts and females from nonheated soil (Fig. 6A). However, due to a high internal variability, no separate cluster was observed for the inoculum cysts, which shared a low similarity with females and soil of both treatments (Fig. 6B).

Pyrosequencing and sequence analysis. Acquired bacterial sequences from females raised in nonheated soil from both G. pallida population microplots were grouped into 333 OTUs ( $>97 \%$ sequence similarity), after excluding OTUs with less than $96 \%$ rRNA gene sequence identity or with only one sequence. An average of 797 total sequences was obtained for females raised in Chavornay soil, while 1,194 were obtained for females raised in Delmsen soil. The OTUs were classified in 10 phyla, 19 classes,
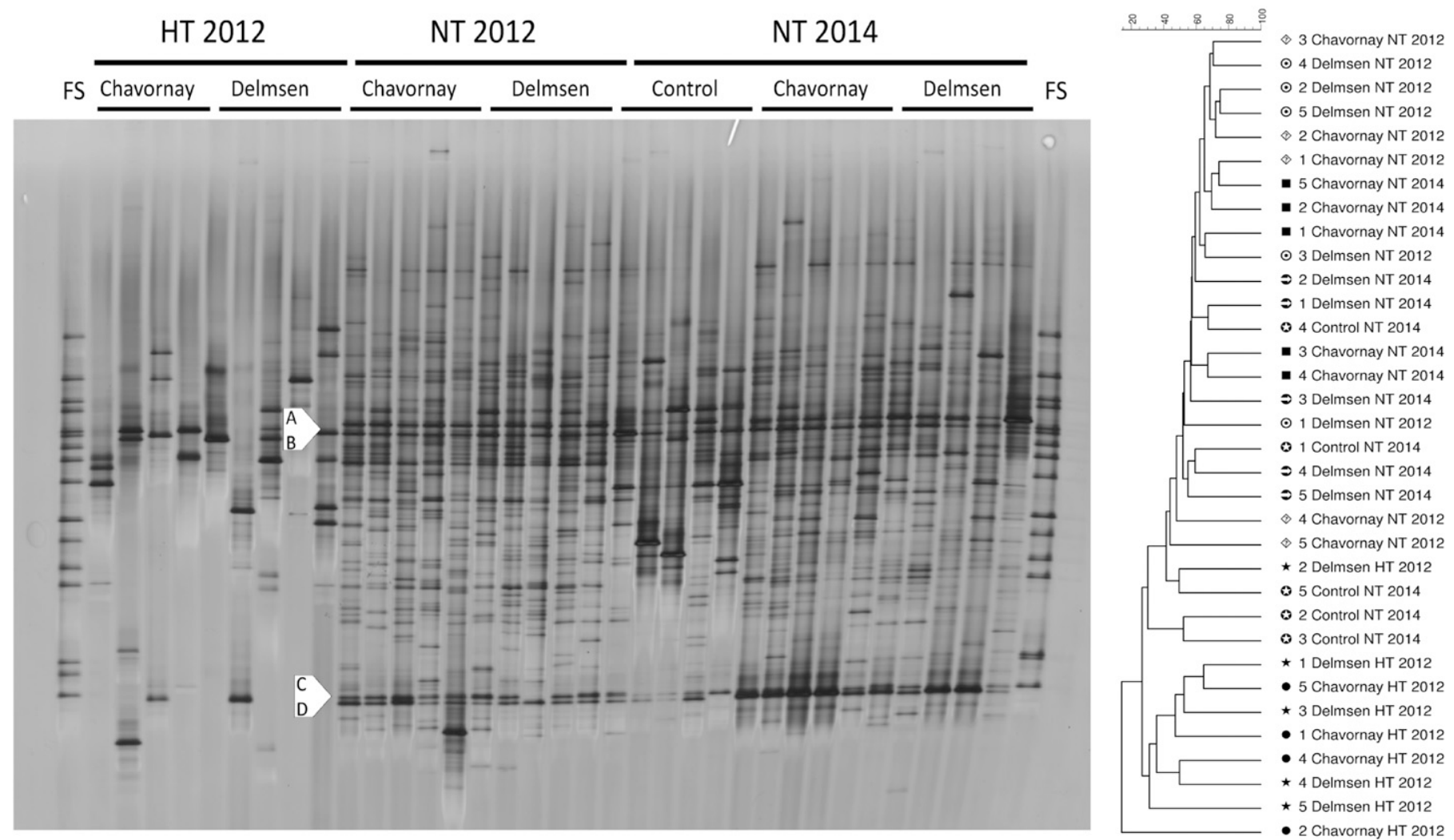

Fig. 4. A, Fungal (internal transcribed spacer) denaturing gradient gel electrophoresis fingerprints for Globodera pallida females collected from heat-treated (HT) and nonheated soil (NT) at 64 days postinoculation (dpi) in 2012 and at 91 dpi in 2014 and B, respective UPGMA cluster. Groups of five/four lines are replicates. FS: fungal standard. Band A, B, C, and D are regarded as dominant bands with identical electrophoretic mobility. In the dendrograms, replicates are labeled 1 to 5. The scale shows similarity values. 
36 orders, 55 families, and 77 genera. Most of the OTUs were affiliated with Proteobacteria (212), followed by Actinobacteria (48) and Bacteroidetes (39). Proteobacteria were dominated by OTUs assigned to Betaproteobacteria (117) and Alphaproteobacteria (71). The phylum Actinobacteria were strongly dominated by the class Actinobacteria (41), and Bacteroidetes by Sphingobacteria (25) and Flavobacteria (11). Of 272 OTUs belonging to 77 genera, $21 \%$ were affiliated to Burkholderia (Betaproteobacteria), $14 \%$ to Ralstonia (Betaproteobacteria), 6\% to Devosia (Alphaproteobacteria), $4 \%$ to Rhizobium (Alphaproteobacteria), and $4 \%$ to Streptomyces (Actinobacteria). A list of the most dominant bacterial OTUs is shown in Table 2 .

In females from the nonheated Chavornay and Delmsen soils, a total of 948 and 1,231 fungal sequences were acquired, respectively. Sequences were grouped into 24 OTUs after excluding OTUs with less than $95 \%$ SH identity, or with only one sequence. The OTUs could be classified to two phyla, three classes, seven orders, four families, and nine genera. A total of 15 of 24 OTUs were affiliated with Ascomycota, seven with Basidiomycota, and two with unidentified uncultured fungi. Within the Ascomycota (15), the majority accounted for Sordariomycetes (8), followed by Dothideomycetes (4) and Euromycetes (3), whereas for Basidiomycota, all were related to Malasseziales (Incertae sedis). At the genus level, the majority was associated with Malassezia (Basidiomycota Incertae sedis), followed by Colletotrichum (Sordariomycetes), and Penicillium (Eurotiomycetes).

Within Malassezia, OTUs containing high number of sequences affiliated with Malassezia restricta, Malassezia sympodialis, and Malassezia globosa were detected in females raised in soil from Chavornay and Delmsen microplots. Among Ascomycota, dominant OTUs assigned to Hirsutella rhossiliensis (Hypocreales), Microdochium bolleyi (Xylariales), and Monographella cucumerina were found in females raised in Chavornay soil but not in Delmsen soil (Table 3). Due to the high variability among replicates within each of the two G. pallida microplot soils (Chavornay and Delmsen), a statistical comparison between these two soils was not conducted.

\section{DISCUSSION}

In this study, the presence of multiple microorganisms associated with females of $G$. pallida was demonstrated. An association of these organisms with the high levels of diseased eggs that were found in the potato monoculture microplots remains to be proven. The content of these eggs appeared coagulated, lysed, degenerated or decayed, as described by Tribe (1977), who referred to such symptoms as eggs diseased by unknown causes. The high abundance of organisms found by culture-independent methods could point to the importance of microbial activities for such pathology. Further identified organisms found at high abundance or reported to be parasitic on nematodes, e.g., $H$. rhossiliensis, may be key players in the dynamic and reduced nematode health observed under this monoculture. The dominance of Malassezia spp. within females from soils of both populations of $G$. pallida suggests an interaction that needs to be further explored. Overall, DGGE fingerprints displayed a high degree of variability among replicates in the nonheated soils suggesting that specific bacterial and fungal ribotypes were not abundant enough to be PCR-amplified, which could mean that no
A

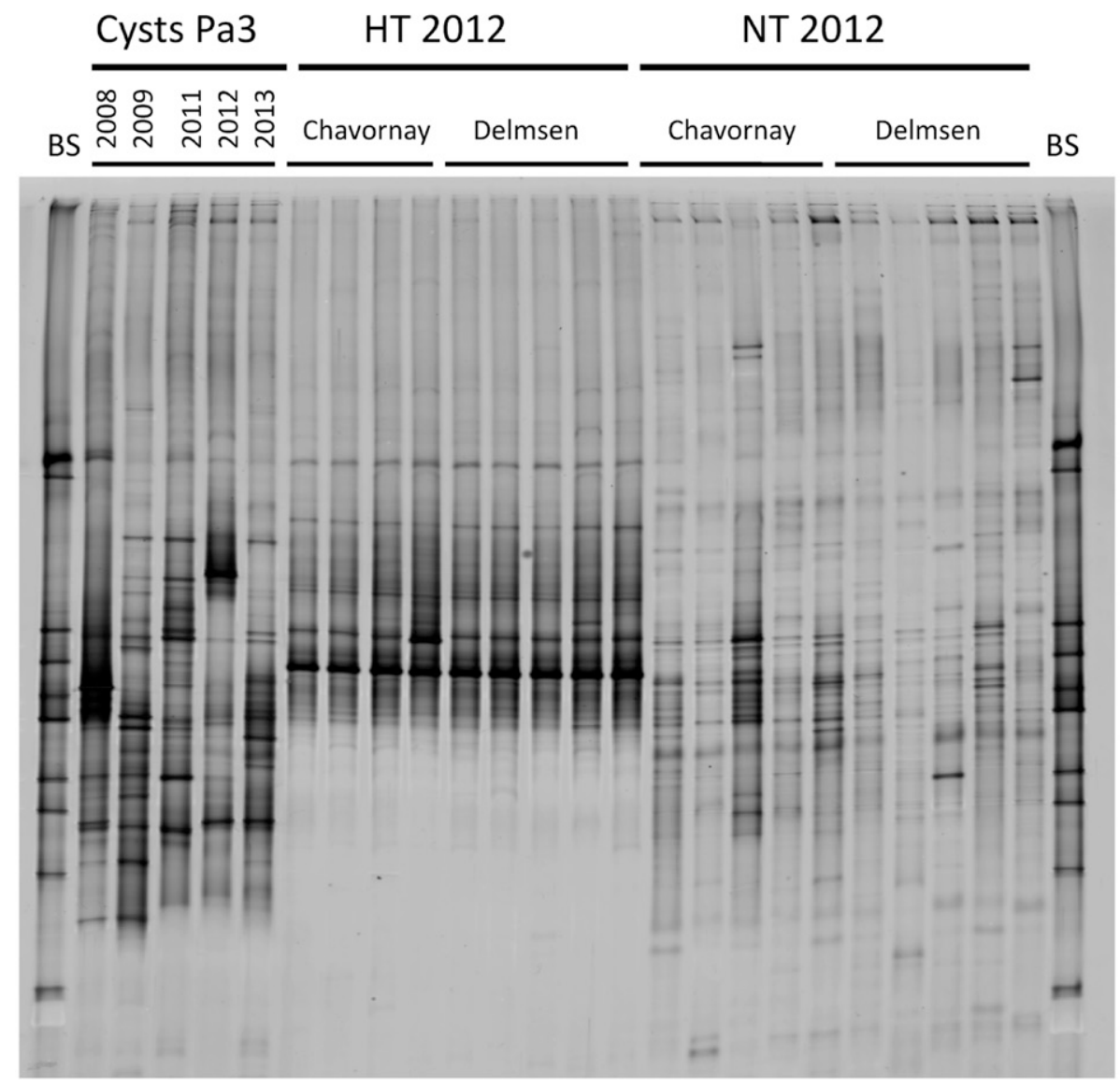

B

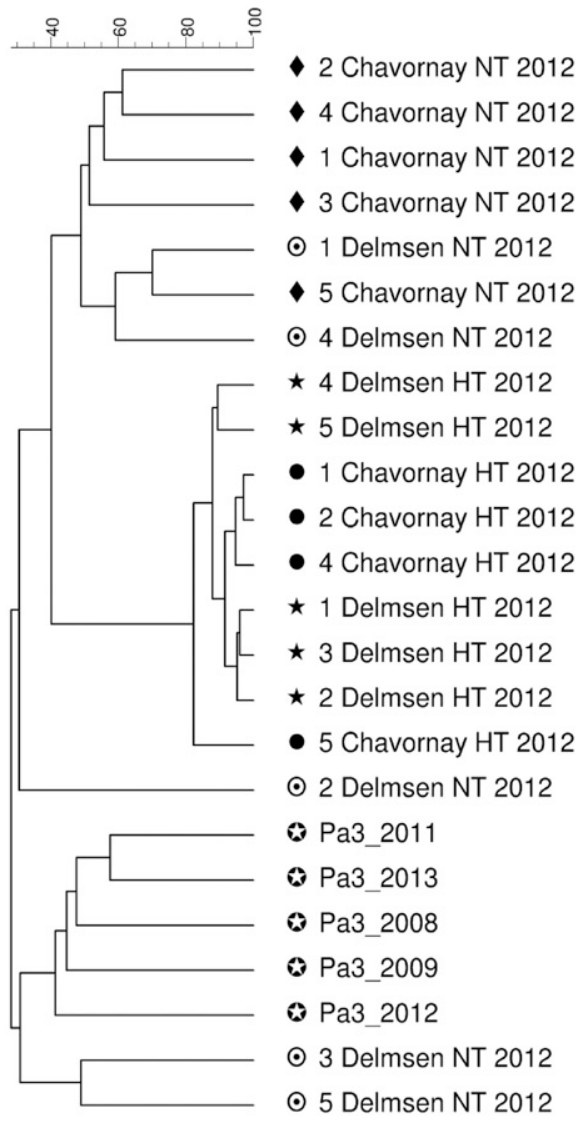

Fig. 5. A, Bacterial (16S rRNA gene) denaturing gradient gel electrophoresis fingerprints for inoculation cysts (Cysts Pa3) and Globodera pallida females in heattreated (HT) and nonheated soil (NT) in 2012 and B, corresponding UPGMA cluster. Groups of five/four lines are replicates. BS: bacterial standard. Inoculation cysts from 5 years are considered replicates. In the dendrograms, replicates are labeled 1 to 5 . The scale shows similarity values. 
stable and reproducible populations were associated with the females developed in these soils. The low similarity between inoculum cysts and newly formed females in bacterial and fungal fingerprints supported that the vast majority of the microorganisms found associated with $G$. pallida females did not derive from the inoculum cysts but from the microplot soil filled in the root observation chambers.

By eliminating most of the soil microbiota, heat treatments have been used to demonstrate the biological nature of specific suppressiveness (Westphal 2005). PCNs generally complete only one generation per growing season; this could explain the lack of significant differences between percentages of diseased eggs in nonheated and heat-treated soil, suggesting that more time may be necessary for measurable suppressiveness. In similar experiments with $H$. schachtii (Crump and Kerry 1987; Westphal and Becker 2001), differences in population development between suppressive and conducive soils were first observed in the second generation of the nematode.

Despite the great percentage of healthy eggs, it appeared that a biotic component may have negatively impacted female fecundity during the monitoring time rather than the nematode eggs directly. Such pathology was also reported for other suppressive soils. Fungal parasites affected the population dynamics of $H$. avenae by reducing the fecundity of females (Kerry et al. 1982). Brachyphoris oviparasitica was first isolated from nematode eggs but later was recognized as a female parasite because the numbers of eggs per female were reduced by almost $60 \%$ compared with females developing in the absence of the fungus (Becker et al. 2013).

Next-generation sequencing complemented the diversity and abundance profiling of females' bacterial and fungal communities obtained by DGGE with the added benefit of time reduction to complete the procedure and without the bias of cultivation. Results obtained by pyrosequencing differed greatly from the species frequently found in other cyst nematodes, which may be mainly explained by differences in isolation procedure, since cyst-colonizing microorganisms have been traditionally determined with culturedependent methods. Since only a minute proportion of the microbial community can be cultivated on laboratory media, the population size and microbial diversity can be substantially underestimated (Bridge and Spooner 2001). DNA-based methods not only detected a greater part of microbial communities, but they also provided further approximation into their structure and functional role, and facilitate the identification of microorganisms involved in suppressiveness against soilborne pathogens (van Elsas et al. 2008). Different DNA fingerprinting approaches like DGGE, cloning, sequencing, and oligonucleotide fingerprinting of rRNA genes (OFRG), with focus on the bacterial and fungal communities associated with cyst nematodes or implicated in their suppressiveness have been used (Borneman and Becker 2007; Nour et al. 2003; Yin et al. 2003a, b). This is the first report of egg health status and associated microbial communities within females of G. pallida based on a cultivationindependent approach.

Although a considerable number of investigations have been conducted on fungal colonization of cyst nematodes, comparatively little is known about the cyst-associated bacterial flora. Most studies have focused on the antagonistic capacities of Pasteuria nishizawae, and rhizobacteria like Bacillus spp. and Pseudomonas spp. (reviewed by Tian et al. 2007). When evaluating the effect of bacteria isolated from cysts against G. pallida, Racke and Sikora (1992) found that $5 \%$ of the bacteria exhibited antagonistic activity against this nematode species. Based on the pyrosequencing data, most OTUs belonged to Alphaproteobacteria, Betaproteobacteria, Actinobacteria, and Sphingobacteria-Flavobacteria groups, which
A

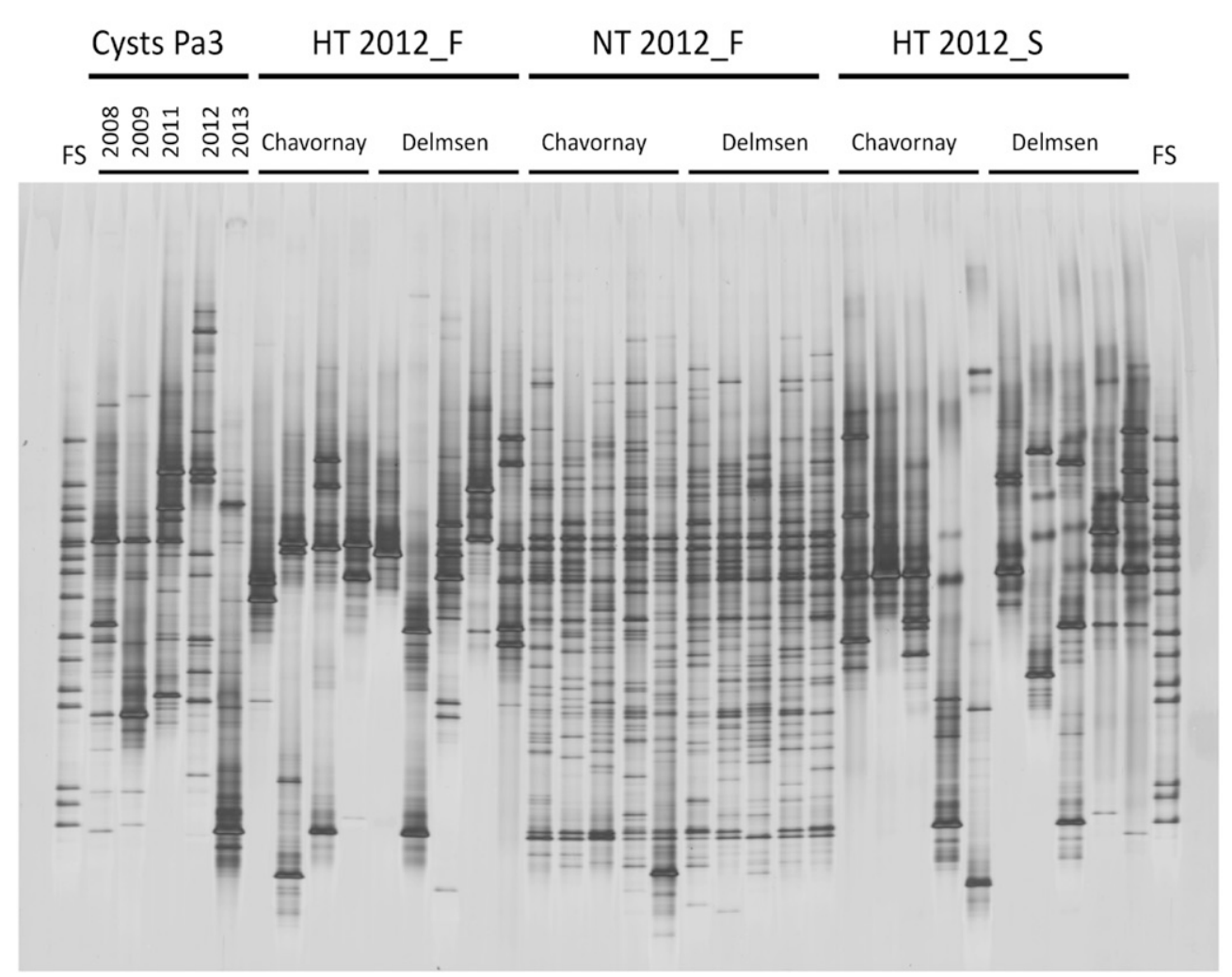

B

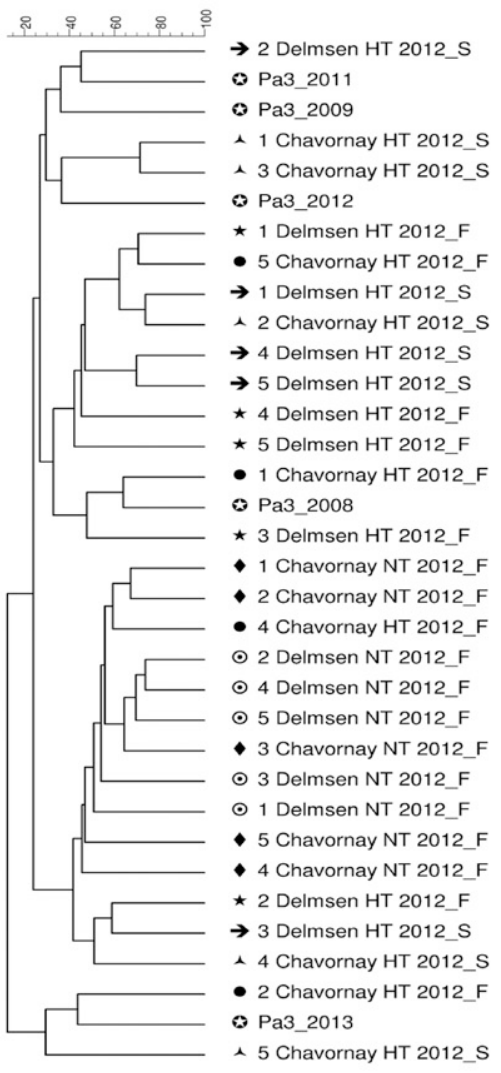

Fig. 6. A, Fungal (internal transcribed spacer) denaturing gradient gel electrophoresis fingerprints for inoculation cysts (Cysts Pa3), for Globodera pallida females from heat-treated (HT_F) and from nonheated soil (NT_F), and for heat-treated soil (HT_S) in 2012 and B, respective UPGMA cluster. Groups of five/four lines are replicates. FS: fungal standard. Inoculation cysts from 5 years are considered replicates. In the dendrograms, replicates are labeled 1 to 5 . The scale shows similarity values. 
were also frequently detected through DNA-based techniques within cysts of $H$. glycines Ichinohe (Nour et al. 2003), and H. schachtii (Yin et al. 2003a). In our study, high proportions of OTUs affiliated with Ralstonia and Burkholderia were found; the last one reported to show antagonistic effects against nematodes (Meyer and Roberts 2002). Ralstonia pickettii, enhanced in females raised in soil from Delmsen microplots, had been reported to significantly reduce soybean damage by root-knot and cyst nematodes (Kloepper et al. 1992). OTUs assigned to some plant pathogens, like Ralstonia solanacearum and $R$. syzygii (Jackson 2009), were also detected. Pantoea agglomerans, a bacteria endophyte isolated from tomato, is capable of reducing penetration by Meloidogyne incognita juveniles, and reducing root galls of tomato (Munif et al. 2013), and was also enriched in females raised in soil from Delmsen microplots. A high number of sequences affiliated with Devosia chinhatensis and Rhodobacter blasticus detected in females isolated from Delmsen microplot soil were also found on baiting juveniles of Meloidogyne hapla Chitwood in three arable soils from Germany (Adam et al. 2014). Brevundimonas vesicularis and Moraxella osloensis, dominant in females from the Delmsen soil, have been reported in the literature to cause human infections (Han and Tarrand 2004; Shang et al. 2012). Moraxella osloensis was also parasitic on the mucous membranes of other warm-blooded animals, nematodes, and slugs (Holt et al. 1994; Tan and Grewal 2001).

The mycoflora of Heterodera spp. has been intensively examined (Carris and Glawe 1989; Kerry 1988; Yin et al. 2003b), but few studies have examined the fungi associated with PCNs. This nematode was believed not to have effective fungal antagonists in agricultural soils until the most commonly occurring fungi in Heterodera spp. were also found in Globodera spp. (Crump 1991). The mycoflora associated with Globodera spp. from potato fields in Europe and South America included the known nematophagous

TABLE 2. Operational taxonomic units (OTU) of the most the dominant bacteria within females of Globodera pallida populations raised in nonheated potato monoculture soil based on the $\mathrm{V} 3-\mathrm{V} 4$ region amplicon pyrosequencing

\begin{tabular}{lc}
\hline OTUs & Identity values $(\%)$ \\
\hline Actinophytocola oryzae & $99.7 ; 99.5-99.7^{\mathrm{a}, \mathrm{b}}$ \\
Aquabacterium parvum & $98.9^{\mathrm{a}}$ \\
Bosea vestrisii & $100^{\mathrm{b}}$ \\
Bradyrhizobium sp./Pseudomonas & $100^{\mathrm{a}}$ \\
carboxydohydrogena & \\
Brevundimonas vesicularis & $100^{\mathrm{a}}$ \\
Burkholderia caledonica & $99.6^{\mathrm{b}}$ \\
Burkholderia kuriensis & $99.1^{\mathrm{a}}$ \\
Candidate division TM7 & $97.9,98.2^{\mathrm{b}, \mathrm{c}}$ \\
Dermacoccus profundi & $99.4,99.7^{\mathrm{a}}$ \\
Devosia chinhatensis & $99.0^{\mathrm{b}, \mathrm{c}}$ \\
Devosia ginsengisoli & $99.3^{\mathrm{a}}$ \\
Moraxella osloensis & $99.6^{\mathrm{a}}$ \\
Pantoea aglomerans & $99.6-99.7^{\mathrm{a}}$ \\
Pelomonas aquaticalPelomonas puraquae & $100^{\mathrm{a}}$ \\
Pelomonas puraquae & $99.8^{\mathrm{a}}$ \\
Ralstonia picketii & $100 ; 99.4-100^{\mathrm{a}, \mathrm{b}}$ \\
Ralstonia solanacearum & $96.7-98.5^{\mathrm{a}}$ \\
Ralstonia syzygii & $98.2-98.5 ; 97.8-98.5^{\mathrm{a}, \mathrm{b}}$ \\
Rhizobium giardinii & $100^{\mathrm{b}}$ \\
Rhodobacter blasticus & $97.7^{\mathrm{b}}$ \\
Sphingopyxis panaciterrae & $100^{\mathrm{a}, \mathrm{b}}$ \\
Streptomyces vinaceus & $100^{\mathrm{b}, \mathrm{c}}$ \\
Uncultured Chitinophagaceae & $100^{\mathrm{b}, \mathrm{c}}$ \\
Uncultured Nakamurella & $99.1^{\mathrm{b}}$ \\
Uncultured Rhizobiales & $99.3^{\mathrm{b}}$ \\
Uncultured Thiotrichaceae & $98.3^{\mathrm{a}}$ \\
Zoogloea ramigera & $100^{\mathrm{b}}$ \\
OAffitions &
\end{tabular}

${ }^{a}$ Affiliations to sequences present in at least three replicates within a population.

b Affiliations to sequences $\geq 100$ times detected in at least one replicate within a population.

c Affiliations to sequences $\geq 400$ times detected in at least one replicate within a population. fungi Cylindrocarpon destructans, Fusarium oxysporum, Gliocladium roseum, Paecilomyces lilacinus, Phoma exigua, Pochonia chlamidosporium, and other fungal species found to grow saprophytically or showing parasitic abilities erratically (Crump and Flynn 1995; Dackman 1990; Jacobs 2000; Morgan-Jones and Rodriguez-Kabana 1986; Roessner 1987; Sikora et al. 1990; Yu and Coosemans 1998). This was corroborated by higher abundance of dominant bands observed in fungal compared with bacterial community profiles, suggesting a higher diversity of predominant ribotypes. These findings were not consistent with the results obtained from the pyrosequencing, where an enhanced number of species was found for bacteria. This inconsistency may be due to the lower resolution power of the ITS2 region compared with the V3-V4 hypervariable region. On the other hand, according to Muyzer and Smalla (1998), bands having the same melting behavior and therefore located at the same position, do not necessarily have the same sequence. This could explain the increased number of species found for bacteria from the pyrosequencing. It may be possible that fewer fungi can concomitantly colonize cysts than bacteria. It was once presumed that only one species of fungus could colonize females or cysts of $H$. glycines (Gintis et al. 1983). While this hypothesis no longer holds, our data supports a scarcer occurrence of fungi compared with bacteria.

Most remarkable was the high abundance of Malassezia, especially Malassezia restricta in G. pallida females from nonheated microplot soils of either Chavornay or Delmsen populations. Although being part of the benign skin flora of humans and animals, yeasts of Malassezia may become pathogenic under certain conditions (Guého-Kellerman et al. 2011). Some described nematophagous fungi, e.g., isolates of $P$. lilacinus can also cause cutaneous infections in humans (Hall et al. 2004). The colonization by Malassezia spp. of substrates high in collagen, a component of the cuticle of G. pallida (Abrantes and Curtis 2002), suggested a potential pathogenic capacity of Malassezia spp. toward G. pallida. The initial neutral lipid content of Globodera spp. (Storey 1983) further supported this hypothesis, since a lipid dependency was suggested for Malassezia species (Guého-Kellerman et al. 2011). Malassezia globosa and Malassezia restricta were also detected in nematodes living in forests (Renker et al. 2003). Moreover, Adam et al. (2014), found DGGE dominant bands related to sequences of Malassezia restricta in samples of three arable soils in Germany and associated to juveniles of Meloidogyne hapla baited in those soils, suggesting an intimate relation with nematodes. In females from Chavornay microplot soil, a high number of sequences were affiliated with Hirsutella rhossiliensis, a fungal pathogen of several cyst nematodes, including G. pallida (Chen and Liu 2005). Sequences affiliated with Microdochium

TABLE 3. Operational taxonomic units (OUTs) of the most dominant fungi within females of Globodera pallida raised in nonheated potato monoculture soil based on internal transcribed spacer 2 region amplicon pyrosequencing

\begin{tabular}{lc}
\hline OTUs & Identity values(\%) \\
\hline Davidiella tassiana & $97.8-100^{\mathrm{a}}$ \\
Hirsutella rhossiliensis & $96.3-100^{\mathrm{a}, \mathrm{b}}$ \\
Malassezia globosa & $99.0^{\mathrm{a}, \mathrm{c}, \mathrm{d}}$ \\
Malassezia restricta & $95.1-100^{\mathrm{a}, \mathrm{b}, \mathrm{c}}$ \\
Malassezia sympodiales & $95.5-99.7^{\mathrm{a}, \mathrm{d}}$ \\
Microdochium bolleyi & $97.4-100^{\mathrm{a}}$ \\
Monographella cucumerina & $95.3-100^{\mathrm{a}}$ \\
Penicillium commune & $95.5-98.4^{\mathrm{b}}$ \\
Penicillium expansum & $95.5-98.4^{\mathrm{a}, \mathrm{c}}$ \\
Uncultured ectomycorrhizal fungus & $95.8-100^{\mathrm{a}, \mathrm{b}, \mathrm{c}}$ \\
\hline
\end{tabular}

a Affiliations to sequences $\geq 100$ times detected in at least one replicate within a population.

b Affiliations to sequences $\geq 800$ times detected in at least one replicate within a population.

c Affiliations to sequences present in at least three replicates within a population.

d Affiliations to sequences $\geq 400$ times detected in at least one replicate within a population. 
bolleyi and Monographella (syn. Plectosphaerella) cucumerina, were also found in high number in samples of this population. Whereas Microdochium bolleyi has been isolated from eggs of the cereal cyst nematode H. avenae (Dackman and Nordbring-Hertz 1985), Monographella cucumerina has been shown to have potential as a biological control agent against PCNs (Atkins et al. 2003; Jacobs 2000).

Findings of this study illustrate the vast diversity and abundance of microbes on PCN females by culture-independent methods. It remains unclear if some of these organisms may be involved in the unknown pathology of "diseased eggs," and such a hypothesis remains to be comprehensively tested. A specific microbiome occupying the microenvironmental niche within $G$. pallida females may be useful for manipulating $G$. pallida population densities. Exploiting their activities has the potential of supporting suppression of this nematode and sustainable production of potato.

\section{ACKNOWLEDGMENTS}

We thank Conicyt for financial support of the first author. Partial support was obtained by the Norwegian Research Council, together with the Foundation for Research Levy on Agricultural Products, the Agricultural Agreement Research Fund, and the Norwegian Food Safety Authority. The support of the Weed Science group and the Institute for Epidemiology and Pathogen Diagnostics of Julius Kühn-Institut during the conduct of this study is appreciated. We thank J. Banyari, T. Bloethe-Hartmann, C. Blümcke, H. Grosse-Lengerich, F. Lange, and A. Windt for technical support; and J. O. Becker, B. Niere, K. Smalla, and S. Schreiter for discussions. The experimental portion of this project was conducted during employment of A. Westphal at the Institute of Plant Protection in Field Crops and Grassland of the Julius Kühn-Institut.

\section{LITERATURE CITED}

Abrantes, I. M. O., and Curtis, R. H. C. 2002. Immunolocalization of a putative cuticular collagen protein in several developmental stages of Meloidogyne arenaria, Globodera pallida and G. rostochiensis. J. Helminthol. 76:1-6.

Adam, M., Westphal, A., Hallmann, J., and Heuer, H. 2014. Specific microbial attachment to root knot nematodes in suppressive soil. Appl. Environ. Microbiol. 80:2679-2686.

Atkins, S. D., Clark, I. M., Sosnowska, D., Hirsch, P. R., and Kerry, B. R. 2003. Detection and quantification of Plectosphaerella cucumerina, a potential biological control agent of potato cyst nematodes, by using conventional PCR, real-time PCR, selective media, and baiting. Appl. Environ. Microbiol. 69:4788-4793.

Becker, J. S., Borneman, J., and Becker, J. O. 2013. Dactylella oviparasitica parasitism of the sugar beet cyst nematode observed in trixenic culture plates. Biol. Control 64:51-56.

Borneman, J., and Becker, J. O. 2007. Identifying microorganisms involved in specific pathogen suppression in soil. Annu. Rev. Phytopathol. 45:153-172.

Bridge, P., and Spooner, B. 2001. Soil fungi: Diversity and detection. Plant Soil 232:147-154.

CABI/EPPO. 1997. Data sheets on quarantine organisms: Globodera rostochiensis and Globodera pallida. Pages 601-606 in: Quarantine Pests for Europe. I. M. Smith, D. G. McNamara, P. R. Scott, M. Holderness, and B. Burger, eds. CAB International, Wallingford, U.K.

Carris, L. M., and Glawe, D. A. 1989. Fungi colonizing cysts of Heterodera glycines. University of Illinois, Urbana-Champaign, Agric. Exp. Stn. Bull. 786.

Chen, S., and Liu, X. 2005. Control of the soybean cyst nematode by the fungi Hirsutella rhossiliensis and Hirsutella minnesotensis in greenhouse studies. Biol. Control 32:208-219.

Crump, D. H. 1991. Fungal species isolated from beet, cereal and potato cyst nematodes. Pages 58-64 in: Methods for Studying Nematophagous Fungi. B. R. Kerry and D. H. Crump, eds. IOBC WPRS Bull. XIV.

Crump, D. H., and Flynn, C. A. 1995. Isolation and screening of fungi for biological control of potato cyst nematodes. Nematologica 41:628-638.

Crump, D. H., and Kerry, B. R. 1987. Studies on the population dynamics and fungal parasitism of Heterodera schachtii in soil from sugar-beet monoculture. Crop Prot. 6:49-55.

Dackman, C. 1990. Fungal parasites of the potato cyst nematode Globodera rostochiensis: Isolation and reinfection. J. Nematol. 22:594-597.

Dackman, C., and Nordbring-Hertz, B. 1985. Fungal parasites of the cereal cyst nematode Heterodera avenae in southern Sweden. J. Nematol. 17: 50-55.
Ding, G. C., Heuer, H., and Smalla, K. 2012. Dynamics of bacterial communities in two unpolluted soils after spiking with phenanthrene: Soil type specific and common responders. Front. Microbiol. 3:290.

European Union. 2007. Council Directive 2007/33/EC of 11 June 2007 on the control of potato cyst nematodes and repealing Directive 69/465/EEC. Off. J. Eur. Union L 156:12-22.

Evans, K., and Haydock, P. P. J. 2000. Potato cyst nematode management present and future. Asp. Appl. Biol. 59:91-97.

FAO. 2008. International Year of the Potato. Food and Agriculture Organization of the United Nations (FAO). http://www.fao.org/potato-2008

Gair R., Mathias P. L., and Harvey, P. N. 1969. Studies of cereal nematode populations and cereal yields under continuous or intensive culture. Ann. Appl. Biol. 63:503-512.

Gintis, B. O., Morgan-Jones, G., and Rodriguez-Kabana, R. 1983. Fungi associated with several developmental stages of Heterodera glycines from Alabama soybean field soil. Nematropica 13:181-200.

Guého-Kellerman, E., Batra, R., and Boekhout, T. 2011. Malassezia Baillon (1889). Pages 1807-1832 in: The Yeasts: A Taxonomic Study. C. Kurtzman, J. W. Fell, and T. Boekhout, eds. Elsevier Science.

Hall, V. C., Goyal, S., Davis, M. D., and Walsh, J. S. 2004. Cutaneous hyalohyphomycosis caused by Paecilomyces lilacinus: Report of three cases and review of the literature. Int. J. Dermatol. 43:648-653.

Han, X. Y., and Tarrand, J. J. 2004. Moraxella osloensis blood and catheter infections during anticancer chemotherapy clinical and microbiologic studies of 10 cases. Am. J. Clin. Pathol. 121:581-587.

Heuer, H., Krsek, M., Baker, P., Smalla, K., and Wellington, E. M. 1997. Analysis of actinomycete communities by specific amplification of genes encoding16SrRNA and gel-electrophoretic separation in denaturing gradients. Appl. Environ. Microbiol. 63:3233-3241.

Heuer, H., Wieland, G., Schoenfeld, J., Schoenwaelder, A., Gomes, N. C. M., and Smalla, K. 2001. Bacterial community profiling using DGGE or TGGE analysis. Pages 177-190 in: Environmental Molecular Microbiology: Protocols and Applications. P. Rouchelle, ed. Horizon Scientific Press, Wymondham, U.K.

Holt, J. G., Krieg, N. R., Sneath, P. H. A., and Staley, J. 1994. Bergey's Manual of Determinative Bacteriology. 9th ed. Williams \& Wilkins, Baltimore, MD.

Jackson, R. W. 2009. Plant Pathogenic Bacteria: Genomics and Molecular Biology. Caister Academic Press, Norfolk, U.K.

Jacobs, H. 2000. Development of a fungal biological control agent for potato cyst nematodes. Ph.D. Thesis. University of Luton, Luton, U.K.

Kerry, B. 1988. Fungal parasites of cyst nematodes. Agric. Ecosyst. Environ. 24:293-305.

Kerry, B. R., and Crump, D. H. 1998. The dynamics of the decline of the cereal cyst nematode, Heterodera avenae, in four soils under intensive cereal production. Fundam. Appl. Nematol. 21:617-625.

Kerry, B. R., Crump, D. H., and Mullen, L. A. 1982. Studies of the cereal cystnematode, Heterodera avenae under continuous cereals, 1975-1978. II. Fungal parasitism of nematode females and eggs. Ann. Appl. Biol. 100: 489-499.

Kloepper, J. W., Rodríguez-Kábana, R., McInroy, J. A., and Young, R. W. 1992. Rhizosphere bacteria antagonistic to soybean cyst (Heterodera glycines) and root-knot (Meloidogyne incognita) nematodes: Identification by fatty acid analysis and frequency of biological control activity. Plant Soil 139:75-84

Kõljalg, U., Nilsson, R. H., and Abarenkov, K. 2013. Towards a unified paradigm for sequence-based identification of fungi. Mol. Ecol. 22:5271-5277.

Meyer, S. L. F., and Roberts, D. P. 2002. Combinations of biocontrol agents for management of plant-parasitic nematode and soilborne plant-pathogenic fungi. J. Nematol. 34:1-8.

Morgan-Jones, G., and Rodriguez-Kabana, R. 1986. Fungi associated with cysts of potato cyst nematodes in Peru. Nematropica 16:21-31.

Munif, A., Hallmann, J., and Sikora, R. A. 2013. The influence of endophytic bacteria on Meloidogyne incognita infection and tomato plant growth. J. ISSAAS 19:68-74.

Muyzer, G., de Waal, E. C., and Uitterlinden, A. G. 1993. Profiling of complex microbial populations by denaturing gradient gel electrophoresis analysis of polymerase chain reaction-amplified genes encoding for 16S rRNA. Appl. Environ. Microbiol. 59:695-700.

Muyzer, G., and Smalla, K. 1998. Application of denaturing gradient gel electrophoresis (DGGE) and temperature gradient gel electrophoresis (TGGE) in microbial ecology. Antonie van Leeuwenhoek 73:127-141.

Ngala, B. M., Haydock, P. P. J., Woods, S., and Back, M. A. 2015. Biofumigation with Brassica juncea, Raphanus sativus and Eruca sativa for the management of field populations of the potato cyst nematode Globodera pallida. Pest Manag. Sci. 71:759-769.

Nour, S. M., Lawrence, J. R., Zhu, H., Swerhone, G. D. W., Welsh, M., Welacky, T. M., and Topp, E. 2003. Bacteria associated with cysts of the soybean cyst nematode (Heterodera glycines). Appl. Environ. Microbiol. 69:607-615. 
Quast, C., Pruesse, E., Yilmaz, P., Gerken, J., Schweer, T., Yarza, P., Peplies, J., and Glöckner, F. O. 2013. The SILVA ribosomal RNA gene database project: Improved data processing and web-based tools. Nucleic Acids Res. 41:D590-D596.

Racke, J., and Sikora, R. A. 1992. Isolation, formulation and antagonistic activity toward the potato cyst nematode Globodera pallida. Soil Biol. Biochem. 24:521-526.

Renker, C., Alphei, J., and Buscot, F. 2003. Soil nematodes associated with the mammal pathogenic fungal genus Malassezia (Basidiomycota: Ustilaginomycetes) in Central European forests. Biol. Fertil. Soils 37:70-72.

Roessner, J. 1987. Pilze als Antagonisten von Globodera rostochiensis. Nematologica 33:106-118.

Schloss, P. D., Westcott, S. L., Ryabin, T., Hall, J. R., Hartmann, M., Hollister, E. B., Lesniewski, R. A., Oakley, B. B., Parks, D. H., Robinson, C. J., Sahl, J. W., Stres, B., Thallinger, G. G., Van Horn, D. J., and Weber, C. F. 2009. Introducing mothur: Open-source, platform-independent, community-supported software for describing and comparing microbial communities. Appl. Environ. Microbiol. 75:7537-7541.

Scholte, K. 2000. Screening of non-tuber bearing Solanaceae for resistance and induction of juvenile hatch of potato cyst nematodes and their potential for trap cropping. Ann. Appl. Biol. 136:239-246.

Schouten, H. J., and Beniers, J. E. 1997. Durability of resistance to Globodera pallida I. Changes in pathogenicity, virulence, and aggressiveness during reproduction on partially resistant potato cultivars. Phytopathology 87:862-867.

Scurrah, M. I., Niere, B., and Bridge, J. 2005. Nematode parasites of Solanum and sweet potatoes. Pages 193-220 in: Plant Parasitic Nematodes in Subtropical and Tropical Agriculture. M. Luc, R. A. Sikora, and J. Bridge, eds. CAB International, Wallingford, U.K.

Shang, S. T., Chiu, S. K., Chan, M. C., Wang, N. C., Yang, Y. S., Lin, J. C., and Chang, F. Y. 2012. Invasive Brevundimonas vesicularis bacteremia: Two case reports and review of the literature. J. Microbiol. Immunol. Infect. 45: 468-472.

Sikora, R., Hiemer, M., and Schuster, R. P. 1990. Reflections on the complexity of fungal infection of nematode eggs and the importance of facultative perthophytic fungal pathogens in biological control of Globodera pallida. Meded. Facu. Landbouwwetensch. Rijksuni. Gent 55:699-712.

Steiner, A. A. 1968. Soilless culture. Pages 324-341 in: Proceedings of the 6th Colloquium of the International Potash Institute. International Potash Institute, Bern, Switzerland.

Stirling, G. R. 1991. Biological Control of Plant-Parasitic Nematodes: Progress Problems and Prospects. CAB International, Wallingford, U.K.

Storey, R. M. J. 1983. The initial neutral lipid reserves of juveniles of Globodera spp. Nematologica 29:144-150.

Tan, L., and Grewal, P. S. 2001. Pathogenicity of Moraxella osloensis, a bacterium associated with the nematode Phasmarhabditis hermaphrodita, to the slug Deroceras reticulatum. Appl. Environ. Microbiol. 67:5010-5016.

Tennant, D. 1975. A test of a modified line intersection method of estimating root length. J. Ecol. 63:995-1001.
Tian, B., Yang, J., and Zhang, K. Q. 2007. Bacteria used in the biological control of plant-parasitic nematodes: Populations, mechanisms of action, and future prospects. FEMS Microbiol. Ecol. 61:197-213.

Tribe, H. T. 1977. Pathology of cyst-nematodes. Biol. Rev. 52:477-507.

United States Department of Agriculture, Animal and Plant Health Inspection Service. 2015. Golden nematode (https://www.aphis.usda.gov/planthealth/ gn) pale nematode (https://www.aphis.usda.gov/planthealth/pcn). USDAAPHIS.

van Elsas, J. D., Speksnijder, A. J., and van Overbeek, L. S. 2008. A procedure for the metagenomics exploration of disease-suppressive soils. J. Microbiol. Methods 75:515-522.

Wang, Y., and Qian, P. Y. 2009. Conservative fragments in bacterial 16S rRNA genes and primer design for $16 \mathrm{~S}$ ribosomal DNA amplicons in metagenomic studies. PLoS One 4:e7401.

Weinert, N., Meincke, R., Gottwald, C., Heuer, H., Gomes, N. C., Schloter, M., Berg, G., and Smalla, K. 2009. Rhizosphere communities of genetically modified zeaxanthin accumulating potato plants and their parent cultivar differ less than those of different potato cultivars. Appl. Environ. Microbiol. 75:3859-3865.

Westphal, A. 2005. Detection and description of soils with specific nematode suppressiveness. J. Nematol. 37:121-130.

Westphal, A., and Becker, J. O. 1999. Biological suppression and natural population decline of Heterodera schachtii in a California field. Phytopathology 89:434-440.

Westphal, A., and Becker, J. O. 2001. Components of soil suppressiveness against Heterodera schachtii. Soil Biol. Biochem. 33:9-16.

Westphal, A., and Xing, L. J. 2011. Soil suppressiveness against the disease complex of the soybean cyst nematode and sudden death syndrome of soybean. Phytopathology 101:878-886.

White, T. J., Bruns, T., Lee, S., and Taylor, J. W. 1990. Amplification and direct sequencing of fungal ribosomal RNA genes for phylogenetics. Pages 315-322 in: PCR Protocols: A Guide to Methods and Applications. M. A. Innis, D. H. Gelfand, J. J. Sninsky, and T. J. White, eds. Academic Press, New York.

Woods, S. R., Haydock, P. P. J., and Edmunds, C. 1999. Mode of action of fosthiazate used for the control of the potato cyst nematode Globodera pallida. Ann. Appl. Biol. 135:409-415.

Yin, B., Valinsky, L., Gao, X., Becker, J. O., and Borneman, J. 2003a. Bacterial rRNA genes associated with soil suppressiveness against the plantparasitic nematode Heterodera schachtii. Appl. Environ. Microbiol. 69: 1573-1580.

Yin, B., Valinsky, L., Gao, X., Becker, J. O., and Borneman, J. 2003b. Identification of fungal rDNA associated with soil suppressiveness against Heterodera schachtii using oligonucleotide fingerprinting. Phytopathology 93:1006-1013.

Yu, Q., and Coosemans, J. 1998. Fungi associated with cysts of Globodera rostochiensis, G. pallida, and Heterodera schachtii; and egg masses and females of Meloidogyne hapla in Belgium. Phytoprotection 79:63-69. 